\title{
锂离子电池负极材料用 $\mathrm{Co}_{3} \mathrm{O}_{4}$ 及其复合材料研究进展

\author{
黄国勇 ${ }^{a}$ 徐盛明 $*, a, b \quad$ 王俊莲 ${ }^{a}$ 李林艳 ${ }^{a}$ 王学军 ${ }^{a}$ \\ ( ${ }^{a}$ 清华大学核能与新能源技术研究院 北京 100084)
} \\ ( ${ }^{b}$ 清华大学精细陶瓷北京市重点实验室 北京 100084)
}

\begin{abstract}
摘要 锂离子电池的性能主要由正、负极材料决定, 负极材料 $\mathrm{Co}_{3} \mathrm{O}_{4}$ 具备理论容量高、振实密度大、化学性质稳定等 特点倍受关注，但存在导电性不好、倍率性能较差等缺点. 解决该问题的手段: 一方面可通过材料的纳米化与特殊形貌 化如球状、纤维状、片状等, 缩短锂离子嵌入和脱出行程; 另一方面可通过材料的复合化, 促进电子的快速传输和缓冲 活性材料在充放电过程中的体积效应. 根据 $\mathrm{Co}_{3} \mathrm{O}_{4}$ 颗粒的形貌特性对现有研究进行了分类与综述, 阐述了改性手段的 可能性机理, 并对如何提高 $\mathrm{Co}_{3} \mathrm{O}_{4}$ 的电化学性能提出了一些想法.
\end{abstract}

关键词 $\mathrm{Co}_{3} \mathrm{O}_{4}$; 锂离子电池; 负极材料; 形貌

\section{Recent Development of $\mathrm{Co}_{3} \mathrm{O}_{4}$ and Its Composites as Anode Materials of Lithium-ion Batteries}

\author{
Huang, Guoyong ${ }^{a} \quad$ Xu, Shengming ${ }^{*, a, b} \quad$ Wang, Junlian $^{a} \quad$ Li, Linyan ${ }^{a} \quad$ Wang, Xuejun ${ }^{a}$ \\ ( ${ }^{a}$ Institute of Nuclear and New Energy Technology, Tsinghua University, Beijing 100084) \\ ( ${ }^{b}$ Beijing Key Lab of Fine Ceramics, Tsinghua University, Beijing 100084)
}

\begin{abstract}
The depletion of non-renewable fossil fuels and environmental issues force us to explore substitutes for fossil fuels, such as solar energy, hydroelectricity, thermal enegy, wind power etc., which are the potential global energy sources in the future. However, most of the renewable energy are typically periodic or intermittent and need to equip with appropriate electrical energy storage devices, such as lithium-ion batteries (LIBs). Novel and advanced anode and cathode materials are the key technologies for high performance LIBs, so various electrode materials with high energy density have been extensively investigated. Cobaltosic oxide $\left(\mathrm{Co}_{3} \mathrm{O}_{4}\right)$, commonly used as the anode materials for LIBs, has attracted extensive interest due to its high theoretical specific capacity $\left(890 \mathrm{mAh} \cdot \mathrm{g}^{-1}\right)$, high tap density and stable chemical properties. However, its practical use is hindered because of the large volume change during repeated lithium uptake and removal reactions, low electronic conductivity, rapid capacity fading upon extended cycling and poor rate capability. To overcome these problems, it is an effective way to prepare nanometer-sized materials with nano-/micrometer-sized structures, which can buffer huge volume changes during the lithium insertion/extraction process and offer extra space for the lithium storage. Up to now, various morphologies of $\mathrm{Co}_{3} \mathrm{O}_{4}$ have been synthesized, such as nanoparticles, nanospheres, nanorods, nanowires, nanotubes, nanosheets, nanoplatelets, nanocubes, hierarchical nanoflowers and some other more complex structures. Another method is to composite with other materials such as carbon or graphene, which has large surface area, open porous structure, great flexibility, chemical stability, high electrical conductivity and the ability to facilitate electron transport within the active sites and effectively alleviate the strain from the volume expansion. In this paper, the recent advances of $\mathrm{Co}_{3} \mathrm{O}_{4}$ and its composites as anode materials of LIBs are reviewed. The researches are classified by the characteristics and morphologies of materials. Their advantages and disadvantages are summarized and the possible reaction mechanisms are explained. In addition, it is also discussed how to improve the electrochemical performance of $\mathrm{Co}_{3} \mathrm{O}_{4}$.

Keywords $\mathrm{Co}_{3} \mathrm{O}_{4}$; lithium-ion batteries; anode materials; morphology
\end{abstract}

\section{1 引言}

众所周知, 一次能源如石油、天然气、煤的开采量 是有限的, 即将枯竭; 同时, 中国已是世界能源消耗第 一大国, 每年的石油消耗量超过 5 亿吨, 且 $60 \%$ 以上用 于交通. 为了降低对石油的依赖性, 减少温室气体的排 放, 改善空气质量, 必须大力扶持与发展新能源汽车,
而锂离子动力电池被认为是其最佳动力源. 同时, 高 效、安全、无污染的再生能源如风能、太阳能等, 具有 明显的间歇性特点, 必须配备合适的能源败备装置即储 能电池. 传统的储能技术如超级电容器、铅酸电池等已 满足不了该市场的需求. 故动力锂电、储能锂电等大型 锂离子电池是目前制约新能源汽车、再生能源领域发展 的瓶颈，当务之急是开发大功率、高比容量、稳定性好、

\footnotetext{
*E-mail: smxu@tsinghua.edu.cn

Received June 23, 2013; published October 27, 2013.

Project supported by the National Natural Science Foundation of China (No. 51274130).

项目受国家自然科学基金(No. 51274130)资助.
} 
使用寿命长、环境适应性强的新型锂离子电池 ${ }^{[1]}$. 锂离 子电池主要由正极材料、负极材料、电解液和隔膜组成. 其工作原理可用 “嵌入式” 机理来描述, 即在充放电过 程中随着电子的转移, 伴随着锂离子在正极、电解液、 负极材料中的嵌入、迁移与脱嵌, 故其性能主要由这三 种材料决定. 由于当前工业化应用的负极材料如石墨、 软碳、硬碳等比容量偏低(石墨理论比容量仅为 372 $\left.\mathrm{mAh} \cdot \mathrm{g}^{-1}\right)$, 锂离子扩散系数较小, 不容易快速充放电, 且耐过充过放电能力差, 难以满足上述需要, 故研究和 开发新型锂离子电池负极材料是当前电化学研究领域 的热门课题 ${ }^{[2]}$.

锂离子电池负极材料种类繁多, 分类方法各异, 以 其跟锂反应的机理不同可大致划分为以下 4 类: (1)嵌入 式反应电极: 以碳素类 ${ }^{[3]}$ 为主, 如石墨、软碳、硬碳、碳 纳米管 ${ }^{[4,5]}$ 、石墨烯 ${ }^{[6]}$ 等; (2)合金化反应电极: $\mathrm{Sn}^{[7]}, \mathrm{Si}^{[8]}$,

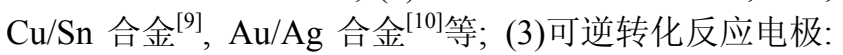
金属氧化物 ${ }^{[11]}$ 、金属硫化物 ${ }^{[12,13]}$ 、金属氮化物 ${ }^{[14]}$ 、金属 磷化物 ${ }^{[15,16]}$ 等; (4) 其他类: $\mathrm{Li}_{4} \mathrm{Ti}_{5} \mathrm{O}_{12}{ }^{[17]}, \mathrm{CuCo}_{2} \mathrm{O}_{4}{ }^{[18]}$, $\mathrm{ZnCo}_{2} \mathrm{O}_{4}{ }^{[19]}, \mathrm{CoMnO}_{4}{ }^{[20]}, \mathrm{ZnMnO}_{4}{ }^{[21]}$ 等. 其中, 金属氧化 物根据脱嵌锂机理不同, 可分为两类: (a)嵌锂氧化物, 锂的嵌入只伴随着材料结构的改变, 如 $\mathrm{TiO}_{2}{ }^{[22]}, \mathrm{WO}_{2}{ }^{[23]}$, $\mathrm{MnO}_{2}{ }^{[24]}$ 等; (b) 嵌锂时形成 $\mathrm{Li}_{2} \mathrm{O}$, 脱锂时可重新形成金 属氧化物, 如 $\mathrm{Co}_{3} \mathrm{O}_{4}{ }^{[25 ~ 27]}, \mathrm{CoO}^{[28]}, \mathrm{Fe}_{3} \mathrm{O}_{4}{ }^{[29]}, \mathrm{Fe}_{2} \mathrm{O}_{3}{ }^{[30]}$, $\mathrm{NiO}^{[31,32]}, \mathrm{MnO}^{[33]}, \mathrm{Mn}_{2} \mathrm{O}_{3}{ }^{[34]}, \mathrm{CuO}^{[35]}, \mathrm{Cu}_{2} \mathrm{O}^{[36]}$ 等. 其中, $\mathrm{Co}_{3} \mathrm{O}_{4}$ 的理论比容量为 $890 \mathrm{mAh} \cdot \mathrm{g}^{-1}$, 为石墨的 2.5 倍, 其密度为石墨的 3 倍, 即体积比容量为石墨的 7.5 倍, 可 大大缩小大型锂电的体积, 且化学性质稳定, 易于合成, 为动力锂电理想负极材料之一; 且对其电化学性能及反 应机理的研究, 可为其他类似廉价过渡金属氧化物(如 铁系、锰系)的开发提供参考, 增大此类负极材料工业化 应用的可能性. 故我们以 $\mathrm{Co}_{3} \mathrm{O}_{4}$ 及其复合负极材料作为 本文综述对象。

\section{$2 \mathrm{Co}_{3} \mathrm{O}_{4}$ 形貌特征对其电化学性能的影响}

锂离子电池负极材料的性能主要由其微观形貌与 颗粒尺寸决定, 故根据 $\mathrm{Co}_{3} \mathrm{O}_{4}$ 的形貌特征(球状、片状、 纤维状及特殊形貌)对现有文献进行了分类介绍.

\section{1 球状}

2000 年, Poizot 等 ${ }^{[37]}$ 首次采用溶剂热法(乙二醇为溶 剂)合成了一系列平均粒径在 100 200 nm 之间的类球 状过渡金属氧化物如 $\mathrm{Co}_{3} \mathrm{O}_{4}, \mathrm{CoO}, \mathrm{NiO}, \mathrm{FeO}$ 等, 发现其 电极具有 $600 \sim 900 \mathrm{mAh} \cdot \mathrm{g}^{-1}$ 的比容量, 且在 $0.2 \mathrm{C}$ 倍率 条件下循环 50 次后, 容量保持率大于 $90 \%$. 该类 $3 \mathrm{~d}$-过 渡金属氧化物属于岩盐相结构, 没有空位可供锂离子嵌 入, 故其提出了全新的反应机理: 金属锂与氧化物发生 氧化还原反应, 生成 $\mathrm{Li}_{2} \mathrm{O}$ 与纳米级金属单质颗粒(约 $2 \sim 8 \mathrm{~nm}$ ), 该纳米颗粒分散在首次嵌锂时形成的 $\mathrm{Li}_{2} \mathrm{O}$ 内 部, 其在室温下显示高电化学活性, 使得反应得以可逆
进行. Sun 等 ${ }^{[38]}$ 采用液相沉淀法, 以乙醇与丙二醇为溶 剂, $170{ }^{\circ} \mathrm{C}$ (油浴)下合成了平均粒径约为 $200 \sim 300 \mathrm{~nm}$ 的 分散性好球形 $\mathrm{Co}_{3} \mathrm{O}_{4}$ 颗粒. 其在 $0.1 \mathrm{C}$ 倍率条件下, 首次 放电容量大于 $1000 \mathrm{mAh} \cdot \mathrm{g}^{-1}, 50$ 次循环后, 容量保持率 仍接近 $100 \%$; 当条件由高倍率 $5 \mathrm{C}$ 变成低倍率 $0.2 \mathrm{C}$ 时, 其容量可由约 $400 \mathrm{mAh} \cdot \mathrm{g}^{-1}$ 恢复至约 $1000 \mathrm{mAh} \cdot \mathrm{g}^{-1}$, 即 材料倍率性能较好. Wang 等 ${ }^{[39]}$ 采用模板法(碳微球为模 板), 通过调整温度、金属浓度及乙醇用量等工艺参数, 可得到不同层数的平均粒径约为 $200 \mathrm{~nm}$ 的空心球形 $\mathrm{Co}_{3} \mathrm{O}_{4}$. 其在 $50 \mathrm{~mA} \cdot \mathrm{g}^{-1}$ 条件下, 比容量约为 $1000 \sim 1500$ $\mathrm{mAh} \cdot \mathrm{g}^{-1}, 30$ 次循环后容量基本无衰减, 并发现随着空 心球层数的增加, 其容量大幅度提升 (图 1). Hong 等 ${ }^{[40]}$ 采用喷雾干燥法合成了平均粒径小于 $60 \mathrm{~nm}$ 的类球状 $\mathrm{Co}_{3} \mathrm{O}_{4}$. 其初始放电容量为 $1100 \mathrm{mAh} \cdot \mathrm{g}^{-1}, 10$ 次循环后 衰减至 $600 \mathrm{mAh} \cdot \mathrm{g}^{-1}, 50$ 次循环后衰减至 $400 \mathrm{mAh} \bullet \mathrm{g}^{-1}$, 容量保持率一般. Zhao 等 ${ }^{[41]}$ 将水热法与溶胶凝胶法结 合，先用葡萄糖制备凝胶，然后将凝胶放入水热釜中， 于 $180{ }^{\circ} \mathrm{C}$ 下合成了分散性好、平均粒径小于 $1 \mu \mathrm{m}$ 的球 形 $\mathrm{Co}_{3} \mathrm{O}_{4}$ 颗粒，但未做电性能表征. 球形是最常见最易 合成的形貌之一, 球状 $\mathrm{Co}_{3} \mathrm{O}_{4}$ 倍率性能一般, 高倍率或 大电流充放电时, 容量相对较低且衰减快, 这可能是由 于纳米球在锂离子嵌入后, 更容易产生团聚, 使得部分 颗粒丧失电化学活性. 空心球结构的性能略好, 可能是 因为空心结构材料比表面积大，有效增大电极与电解液 接触面积; 同时, 可利用空心的优势来缓冲活性材料在 充放电过程中的体积效应.
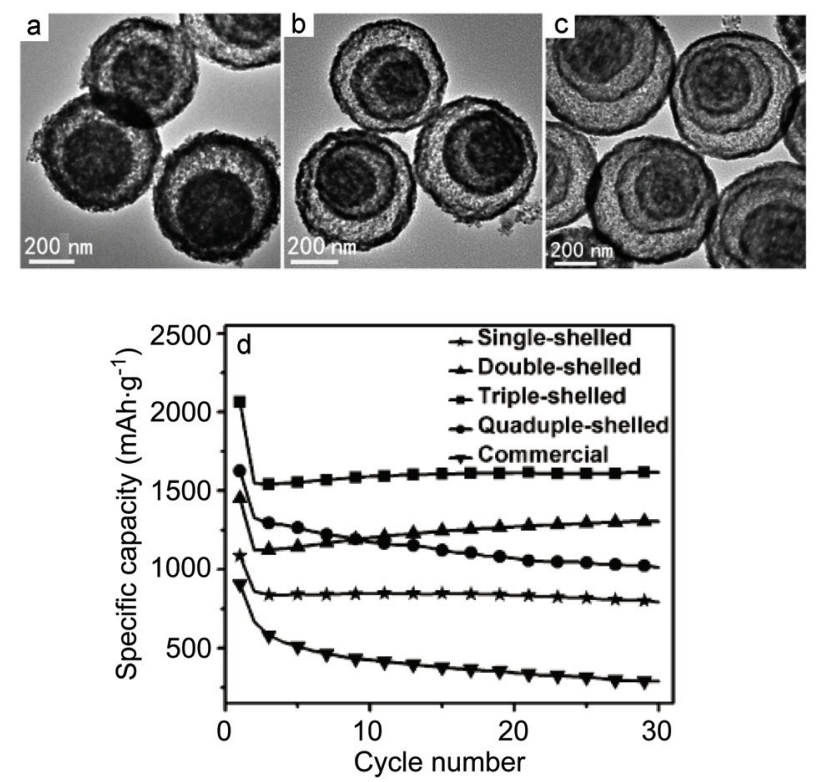

图 1 不同层数中空 $\mathrm{Co}_{3} \mathrm{O}_{4}$ 微球的 TEM 图(a. 二层; b. 三层; c. 四层) 和其在 $50 \mathrm{~mA} \cdot \mathrm{g}^{-1}$ 恒电流充放电条件下的放电容量 - 循环数曲线 $(\mathrm{d})^{[39]}$ Figure 1 (a), (b), (c) TEM images of double-, triple-, and quadrupleshelled $\mathrm{Co}_{3} \mathrm{O}_{4}$ hollow micro-spheres and (d) discharge capacity versus cycle number for the prepared $\mathrm{Co}_{3} \mathrm{O}_{4}$ hollow micro-spheres at a current density of $50 \mathrm{~mA} \cdot \mathrm{g}^{-1[39]}$ 


\section{2 片状}

Zhan 等 ${ }^{[42]}$ 采用水热法合成了分散性好、无团聚的 六方片状 $\mathrm{Co}_{3} \mathrm{O}_{4}$, 片直径约为 $50 \mathrm{~nm}$, 厚度约为 $10 \mathrm{~nm}$. 其在 $50 \mathrm{~mA} \cdot \mathrm{g}^{-1}$ 条件下, 初始放电容量为 $2150 \mathrm{mAh} \cdot \mathrm{g}^{-1}$, 后续放电容量均高于 $1400 \mathrm{mAh} \cdot \mathrm{g}^{-1}$, 且 30 次循环后, 容 量无衰减, 容量保持率较好(图 2). $\mathrm{Lu}$ 等 ${ }^{[43]}$ 采用微波法 合成了直径约 $1 \sim 2 \mu \mathrm{m}$, 厚度约为 $50 \mathrm{~nm}$ 的多孔六方片 状 $\mathrm{Co}_{3} \mathrm{O}_{4}$. 其在 $1 \mathrm{C}$ 倍率条件下, 首次放电容量为 811 $\mathrm{mAh} \cdot \mathrm{g}^{-1}, 30$ 次循环后容量保持率约为 $75 \%$; 并当条件 由高倍率 $5 \mathrm{C}$ 变成低倍率 $0.2 \mathrm{C}$ 时, 其容量可由约 350 $\mathrm{mAh} \cdot \mathrm{g}^{-1}$ 恢复至约 $700 \mathrm{mAh} \cdot \mathrm{g}^{-1}$. Yan 等 ${ }^{[44]}$ 在室温下通过 化学沉淀法制备了前驱体 $\mathrm{Co}_{3}\left[\mathrm{Co}(\mathrm{CN})_{6}\right]_{2}$, 然后在 450 $850{ }^{\circ} \mathrm{C}$ 下炦烧合成了边长约为 $50 \sim 100 \mathrm{~nm}$ 的多孔立方 块状 $\mathrm{Co}_{3} \mathrm{O}_{4}$. 并发现炦烧温度决定了材料的电化学性能: 在 $550{ }^{\circ} \mathrm{C}$ 时, 其比容量最高约为 $1000 \mathrm{mAh} \cdot \mathrm{g}^{-1}$.
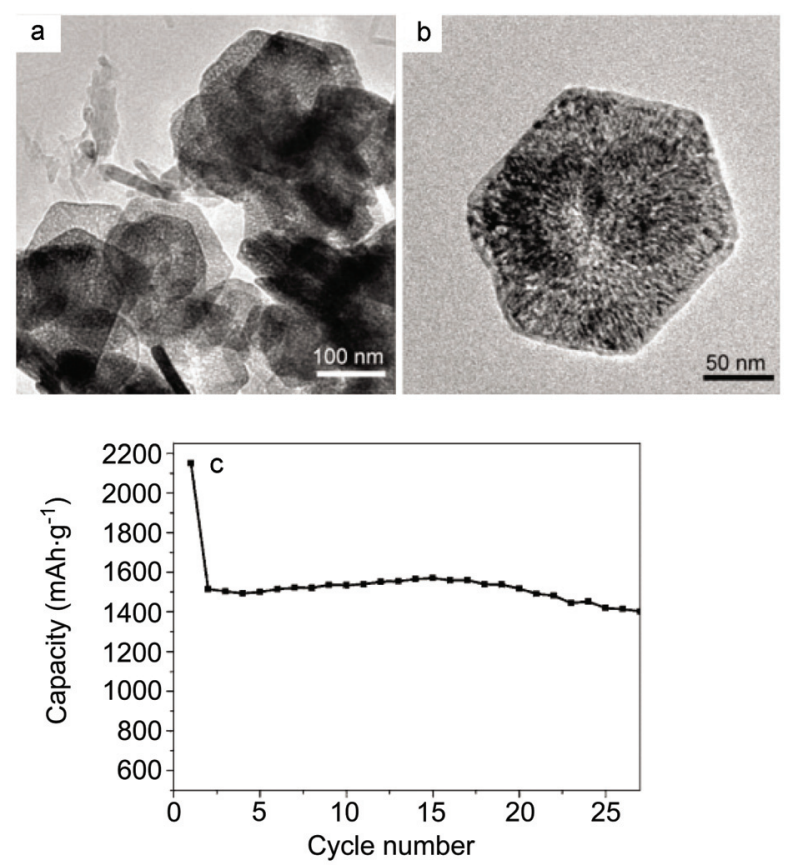

图 2 多孔六方片状 $\mathrm{Co}_{3} \mathrm{O}_{4}$ 在不同放大倍数下的 TEM 图(a, b) 和其在 $50 \mathrm{~mA} \cdot \mathrm{g}^{-1}$ 条件下的放电容量 - 循环数曲线 $(\mathrm{c})^{[42]}$

Figure 2 (a) and (b) TEM images of porous $\mathrm{Co}_{3} \mathrm{O}_{4}$ nanosheets at different magnifications and (c) discharge capacity versus cycle number for the porous $\mathrm{Co}_{3} \mathrm{O}_{4}$-based anode materials at a current density of 50 $\mathrm{mA} \cdot \mathrm{g}^{-1[42]}$

Dong 等 ${ }^{[45]}$ 采用溶剂热法, 以环烷酸钴为钴源、二甲 苯为溶剂、 $160{ }^{\circ} \mathrm{C}$ 下合成了平均粒径在 $100 \mathrm{~nm} \sim 1 \mu \mathrm{m}$ 范围内可控制备的六方片状 $\mathrm{Co}(\mathrm{OH})_{2}$ (厚度约为 $10 \sim 20$ $\mathrm{nm})$, 然后氧化制得 $\mathrm{Co}_{3} \mathrm{O}_{4}$. Tian 等 ${ }^{[46]}$ 以油酸钠为分散 剂, 乙酸钴为钴源, 氨水为沉淀剂, 采用过氧化氢直接 氧化法制备了平均粒径约为 $10 \sim 20 \mathrm{~nm}$, 厚度约为 $1 \sim 2$ $\mathrm{nm}$ 的四方片状纳米颗粒, 其可均匀分散于水中, 静置 几个月不沉降. $\mathrm{Li}$ 等 ${ }^{[47]}$ 采用水热法(水和正丁醇做溶剂) 合成了平均粒径约为 $20 \mathrm{~nm}$, 厚度约为 $1 \sim 2 \mathrm{~nm}$ 的四方 片状 $\mathrm{Co}_{3} \mathrm{O}_{4}$, 分散性好, 结晶完整. 但遗憾的是其均未
做电化学性能表征. 与球形 $\mathrm{Co}_{3} \mathrm{O}_{4}$ 相比, 片状材料的倍 率性能相对较好, 这可能是由于片状颗粒的尺寸更小 (厚度均为纳米级), 比表面积较大, 便于锂离子的嵌入 与脱出, 有利于大电流或高倍率下充放电.

\section{3 纤维状}

$\mathrm{Nam}$ 等 ${ }^{[48]}$ 采用模板法, 以生物病毒(M13 Virus)为 骨架负载 $\mathrm{Co}_{3} \mathrm{O}_{4}$ 颗粒，制备了长度大于 $2.0 \mu \mathrm{m}$, 管径小 于 $10 \mathrm{~nm}$ 的纤维状材料, 其电化学性能一般, 容量约为 $600 \sim 800 \mathrm{mAh} \cdot \mathrm{g}^{-1}$. Shim 等 ${ }^{[49]}$ 以枯草杆菌为模板, 以上 述类似方法合成了长度约为 $2 \sim 5 \mu \mathrm{m}$, 直径约为 $500 \mathrm{~nm}$ 的中空 $\mathrm{Co}_{3} \mathrm{O}_{4}$ 纳米线. 在 $240 \mathrm{~mA} \cdot \mathrm{g}^{-1}$ 条件下, 其首次放 电容量约为 $1500 \mathrm{mAh} \cdot \mathrm{g}^{-1}, 20$ 次循环后仍保持 1000 $\mathrm{mAh} \cdot \mathrm{g}^{-1}$. $\mathrm{Li}$ 等 ${ }^{[50]}$ 先采用水热法合成前驱体 $\mathrm{Co}(\mathrm{NA}) \mathrm{H}$, 然后耘烧合成了长度大于 $10 \mu \mathrm{m}$, 管径小于 $100 \mathrm{~nm}$ 的纤 维状 $\mathrm{Co}_{3} \mathrm{O}_{4}$. 在 $0.1 \mathrm{C}$ 倍率条件下, 首次放电容量约为 $1200 \sim 1400 \mathrm{mAh} \cdot \mathrm{g}^{-1}, 30$ 次循环后容量保持率大于 $90 \%$. Wang 等 ${ }^{[51]}$ 采用模板法, 使前驱体 $\mathrm{Co}\left(\mathrm{CO}_{3}\right)_{0.5}(\mathrm{OH})$ • $0.11 \mathrm{H}_{2} \mathrm{O}$ 因氢键吸附在二氧化钛表面, 然后升温至 350 ${ }^{\circ} \mathrm{C}$ 反应 $4 \mathrm{~h}$, 分解得 $\mathrm{Co}_{3} \mathrm{O}_{4}$ 纳米阵列, 纳米线长度约为 $20 \sim 50 \mathrm{~nm}$, 管径约为 $0.3 \sim 0.4 \mathrm{~nm}$. 他们重点分析了其 高倍率下的电化学性能: 发现在 $1.5 \mathrm{C}, 15 \mathrm{C}, 30 \mathrm{C}$ 倍率条 件下, 其初始放电容量均大于 $800 \mathrm{mAh} \cdot \mathrm{g}^{-1} ; 30$ 次循环 后， $1.5 \mathrm{C}$ 倍率条件下容量基本无衰减， $15 \mathrm{C}$ 倍率条件下 容量保持率大于 $70 \%, 30 \mathrm{C}$ 倍率条件下容量保持率大于 $37.5 \%$, 倍率性能优异(图 3). $\mathrm{Li}$ 等 ${ }^{[52]}$ 采用上述类似的方 法在钛筞上合成了长度约为 $15 \mu \mathrm{m}$, 直径约为 $500 \mathrm{~nm}$ 的 $\mathrm{Co}_{3} \mathrm{O}_{4}$ 纳米线阵列. 其在 $20 \mathrm{C}$ 倍率条件下, 20 次循环后 容量保持率约为 $75 \%$; 在 $50 \mathrm{C}$ 倍率条件下, 20 次循环后 容量保持率约为 $50 \%$. Xue 等 ${ }^{[53]}$ 采用同样的模板法在铜 䇴表面也合成了直径约为 $3 \mathrm{~nm}$ 的 $\mathrm{Co}_{3} \mathrm{O}_{4}$ 纳米线阵列. 其 在 $4 \mathrm{C}$ 倍率条件下, 首次放电容量大于 $1500 \mathrm{mAh} \cdot \mathrm{g}^{-1}, 20$ 次循环后容量仍大于 $800 \mathrm{mAh} \cdot \mathrm{g}^{-1}$; 在 $610 \mathrm{C}$ 倍率条件下 充电后(即充电时间约为 $6 \mathrm{~s}$ ), 恢复至 $0.5 \mathrm{C}$ 倍率条件下 放电, 其容量仍可恢复至 $1167 \mathrm{mAh} \cdot \mathrm{g}^{-1}$. Lou 等 ${ }^{[54]}$ 采用 液相沉淀法合成了长度大于 $2 \mu \mathrm{m}$, 管径约 $200 \mathrm{~nm}$ 的中 空纤维状 $\mathrm{Co}_{3} \mathrm{O}_{4}$. 在 $50 \mathrm{~mA} \cdot \mathrm{g}^{-1}$ 条件下, 前 30 次循环后 容量仍大于 $900 \mathrm{mAh} \cdot \mathrm{g}^{-1}$, 但接下来 50 个循环容量衰减 迅速, 最终至 $400 \mathrm{mAh} \cdot \mathrm{g}^{-1}$. Ding 等 ${ }^{[55]}$ 采用电纺丝技术, 将硝酸钴、聚乙烯基吡咯烷酥(PVP)溶解于乙醇中，电纺 丝后形成凝胶纤维膜, 在 $500 \sim 750{ }^{\circ} \mathrm{C}$ 空气中炦烧 $10 \mathrm{~h}$ 后, 即可得到长度为 $0.7 \sim 1.0 \mu \mathrm{m}$, 管径约为几十纳米的 $\mathrm{Co}_{3} \mathrm{O}_{4}$ 纳米纤维. 但其电化学性能一般: 首次放电容量 为 $1100 \mathrm{mAh} \cdot \mathrm{g}^{-1}, 10$ 次循环后即衰减至 $800 \mathrm{mAh} \cdot \mathrm{g}^{-1}$ 以 下, 40 次后衰减至 $400 \mathrm{mAh} \cdot \mathrm{g}^{-1}$. Xu 等 ${ }^{[56]}$ 采用微乳液法, 以溴化十六烷三甲基铵/水/环已烷/ $n$-戊醇组成四元微乳 液, 合成前驱体材料 $\mathrm{CoC}_{2} \mathrm{O}_{4}$, 然后 $450{ }^{\circ} \mathrm{C}$ 炦烧 $3 \mathrm{~h}$ 后, 制备了长度大于 $4 \mu \mathrm{m}$, 管径约 $80 \sim 150 \mathrm{~nm}$ 的 $\mathrm{Co}_{3} \mathrm{O}_{4}$ 纤 维. Keng 等 ${ }^{[57]}$ 采用模板法, 将钴盐固定在聚合物高分子 
模板上, 然后在 $175^{\circ} \mathrm{C}$ 氧气氛围下, 炦烧成中空 $\mathrm{CoO}$ 与 $\mathrm{Co}_{3} \mathrm{O}_{4}$ 纳米线, 其中 $\mathrm{Co}_{3} \mathrm{O}_{4}$ 纳米线长度大于 $4 \mu \mathrm{m}$, 管径 约 $40 \mathrm{~nm}$. 但两者均未做电化学性能表征. 纤维阵列 $\mathrm{Co}_{3} \mathrm{O}_{4}$ 的倍率性能优异, 其在高倍率 $20 \mathrm{C}, 40 \mathrm{C}, 50 \mathrm{C}$ 下均 可以保持较高的比容量值. 这可能是由于纳米线、纳米 棒、纳米管等纤维结构, 与球形相比其自身结构相更稳 定, 可以更好的缓解充放电过程中由材料体积膨胀所引 起的应力; 且阵列属于二维纳米结构, 便于电解液的扩 散, 缩短了锂离子传输距离, 进一步促进了电极反应.
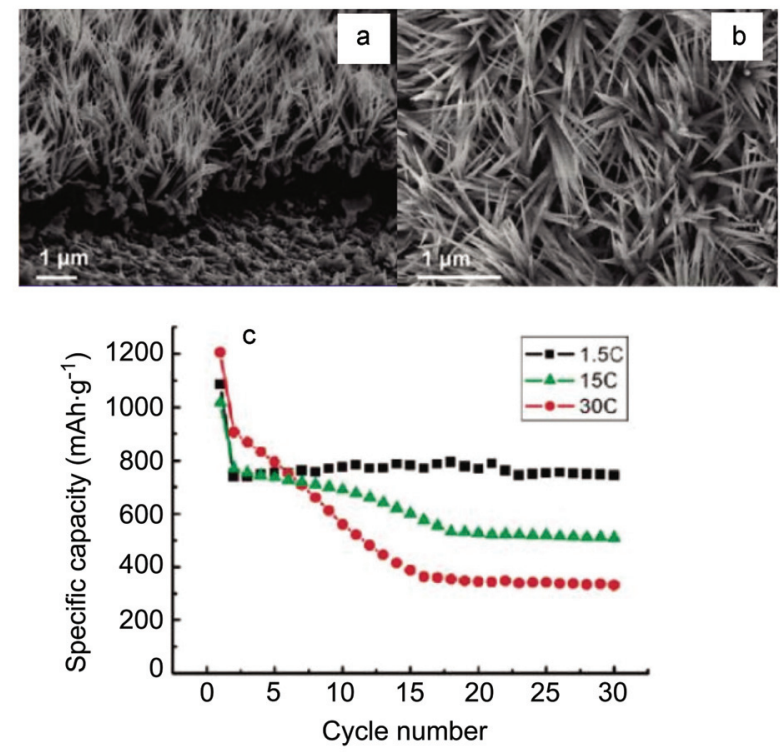

图 3 附着于钛䈃上的 $\mathrm{Co}_{3} \mathrm{O}_{4}$ 纳米线阵列在不同放大倍数下的 SEM 图 $(a, b)$ 和其在不同倍率下的放电容量 - 循环数曲线 $(c)^{[51]}$

Figure 3 (a) and (b) SEM images of $\mathrm{Co}_{3} \mathrm{O}_{4}$ nanobelt array attached to Ti foil at different magnifications and (c) discharge capacity versus cycle number for the prepared $\mathrm{Co}_{3} \mathrm{O}_{4}$ nanobelt array at different discharge $\operatorname{rates}(1.5 \mathrm{C}, 15 \mathrm{C} \text { and } 30 \mathrm{C})^{[51]}$

\section{4 特殊形貌}

$\mathrm{Xu}$ 等 ${ }^{[58]}$ 采用熔融法合成了多孔分层的絮状不规则 形貌的 $\mathrm{Co}_{3} \mathrm{O}_{4}$. 其在 $0.1 \mathrm{C}$ 倍率条件下, 首次放电容量为 $1336 \mathrm{mAh} \cdot \mathrm{g}^{-1}, 50$ 次循环后, 容量仍保持在 $680 \mathrm{mAh} \cdot$ $\mathrm{g}^{-1}$ 以上. Chou 等 ${ }^{[59]}$ 采用电化学沉积法, 在电流密度为 $1.0 \mathrm{~mA} / \mathrm{cm}^{2}$ 的条件下, 将一定浓度的硝酸钴溶液在镍电 极上沉积得到前驱体, 然后在 $300{ }^{\circ} \mathrm{C}$ 下热处理制备了 多孔 $\mathrm{Co}_{3} \mathrm{O}_{4}$ 薄膜. 其在 $100 \mathrm{~mA} \cdot \mathrm{g}^{-1}$ 条件下, 首次放电容 量约为 $1100 \mathrm{mAh} \cdot \mathrm{g}^{-1}, 50$ 次循环后约为 $500 \mathrm{mAh} \cdot \mathrm{g}^{-1}$. Rui 等 ${ }^{[60]}$ 采用水热法合成前驱体 $\mathrm{Co}\left(\mathrm{CO}_{3}\right)_{0.5}(\mathrm{OH})$ • $0.11 \mathrm{H}_{2} \mathrm{O}$, 然后在 $400{ }^{\circ} \mathrm{C}$ 下炦烧 $2 \mathrm{~h}$ 后, 制得平均直径约 $1 \sim 2 \mu \mathrm{m}$ 的海胆状 $\mathrm{Co}_{3} \mathrm{O}_{4}$. 在 $1 \mathrm{C}$ 倍率条件下, 循环 100 次后容量仍大于 $1100 \mathrm{mAh} \cdot \mathrm{g}^{-1}$, 基本无衰减, 容量高, 保持率好(图 4). Xiong 等 ${ }^{[61]}$ 采用上述类似方法也合成了 花状 $\mathrm{Co}_{3} \mathrm{O}_{4}$, 并通过改变工艺参数, 使得颗粒尺寸可控 调节. 且以此花状 $\mathrm{Co}_{3} \mathrm{O}_{4}$ 为前驱体, 通过 $\mathrm{C}_{2} \mathrm{H}_{2}$ 还原后, 可得 $\mathrm{CoO} / \mathrm{C}$ 复合材料. 结果显示: 后者的比容量要高于
前者, 但容量保持率要比前者略差. Wang 等 ${ }^{[62]}$ 采用水 热法先合成了前驱体 $\mathrm{Co}(\mathrm{OH}) \mathrm{F}$ ，经 $400{ }^{\circ} \mathrm{C}$ 煅烧后制得 平均直径约为 $10 \mu \mathrm{m}$ 的六角特殊形貌 $\mathrm{Co}_{3} \mathrm{O}_{4}$, 但电化学 性能一般. Wang 等 ${ }^{[63]}$ 采用旋转涂布技术, 将硝酸钴有 机溶剂制成薄膜, 然后在 $300 \sim 600{ }^{\circ} \mathrm{C}$ 下, 氧气与氮气 氛围下热解分别制备了 $\mathrm{CoO}$ 与 $\mathrm{Co}_{3} \mathrm{O}_{4}$ 薄膜，该膜由直径 小于 $50 \mathrm{~nm}$ 的小颗粒组成. 但未做电性能表征. 特殊形 貌如花状等既可阻止团聚，保持纳米结构的稳定性，提 高循环性能; 又能增大与电解液的接触面积, 缩短锂离 子与电子的扩散距离, 使其表现出良好的循环性能与倍 率性能.
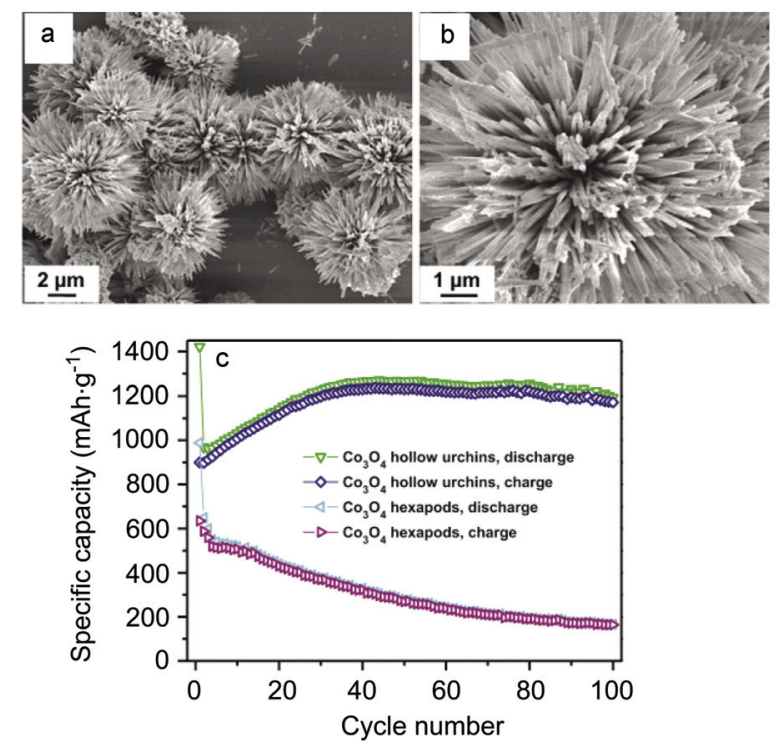

图 4 海胆状 $\mathrm{Co}_{3} \mathrm{O}_{4}$ 球在不同放大倍数下的 $\operatorname{SEM}$ 图 $(\mathrm{a}, \mathrm{b})$ 和其在 $1 \mathrm{C}$ 倍 率下的循环性能曲线(c) ${ }^{[60]}$

Figure 4 (a) and (b) SEM images of urchin-like $\mathrm{Co}_{3} \mathrm{O}_{4}$ spheres at different magnifications and (c) cycling performances of urchin-like $\mathrm{Co}_{3} \mathrm{O}_{4}$ spheres at a rate of $1 \mathrm{C}^{[60]}$

\section{3 基于 $\mathrm{Co}_{3} \mathrm{O}_{4}$ 复合负极材料的研究}

\section{$3.1 \mathrm{Co}_{3} \mathrm{O}_{4}$ 与碳素类复合}

碳素类负极材料导电性好, 化学性能稳定, 机械强 度高，本身也有储锂容量，常常用来对各种其他锂离子 电极材料进行包覆或混用, 提高其电化学性能. $\mathrm{Co}_{3} \mathrm{O}_{4}$ 材料的导电性不好, 故 $\mathrm{Co}_{3} \mathrm{O}_{4}$ 与碳素类的复合材料越来 越多.

\subsection{1 $\mathrm{Co}_{3} \mathrm{O}_{4} /$ 碳复合材料}

Zhang 等 ${ }^{[64]}$ 采用电纺丝技术合成了 $\mathrm{Co}_{3} \mathrm{O}_{4}$ /碳复合材 料. 其以聚丙烯腈(PAN)为碳源与电纺丝基底材料、醋 酸钴为金属源、 $N, N$-二甲基甲酰胺( DMF)为溶剂，经电 纺丝、在空气中不同温度煅烧后, 制得碳纤维直径约为 $200 \sim 300 \mathrm{~nm}$, 表面镶嵌着直径约为 $50 \sim 100 \mathrm{~nm}$ 的 $\mathrm{Co}_{3} \mathrm{O}_{4}$ 颗粒的复合材料. 与单一 $\mathrm{Co}_{3} \mathrm{O}_{4}$ 相比, 复合材料 的初始电容量略有降低，但后续容量保持率更好，且容 量倍率性能大幅度提升: 在 $100 \mathrm{~mA} \cdot \mathrm{g}^{-1}$ 条件下, 复合材 
料首次放电容量约为 $800 \mathrm{mAh} \cdot \mathrm{g}^{-1}, 20$ 次循环后容量约 为 $580 \mathrm{mAh} \cdot \mathrm{g}^{-1}$; 而 $\mathrm{Co}_{3} \mathrm{O}_{4}$ 首次放电容量大于 $1200 \mathrm{mAh} \cdot$ $\mathrm{g}^{-1}, 20$ 次循环后, 容量仅为 $240 \mathrm{mAh} \cdot \mathrm{g}^{-1}$; 且在相同倍 率条件下如 $2 \mathrm{C}, 4 \mathrm{C}, 8 \mathrm{C}$ 等, 复合材料容量是单一 $\mathrm{Co}_{3} \mathrm{O}_{4}$ 容量的 2 倍(图 5). Wang 等 ${ }^{[65]}$ 合成了可自堆积的相互交 替叠加的层状 $\mathrm{Co}_{3} \mathrm{O}_{4} / \mathrm{C}$ 复合材料, 每层厚度约为 $40 \mathrm{~nm}$. 在 $178 \mathrm{~mA} \cdot \mathrm{g}^{-1}$ 条件下, 其首次放电容量约为 1200 $\mathrm{mAh} \cdot \mathrm{g}^{-1}, 50$ 次循环后基本无衰减. Wang 等 ${ }^{[66]}$ 采用液相 共沉淀法与热解碳还原法制备了 $\mathrm{Co}_{3} \mathrm{O}_{4} / \mathrm{NiO} / \mathrm{C}$ 三元复合 材料. 在相同条件下 $\left(100 \mathrm{~mA} \cdot \mathrm{g}^{-1}\right)$, 该复合材料的容量 保持率大幅提升: 其循环 60 次后容量仍大于 $400 \mathrm{mAh}$ $\mathrm{g}^{-1}$, 而单一 $\mathrm{Co}_{3} \mathrm{O}_{4}$ 的容量已衰减至 $200 \mathrm{mAh} \cdot \mathrm{g}^{-1}$ 以下. Zhan 等 ${ }^{[67]}$ 制备了 $\mathrm{Co}_{3} \mathrm{O}_{4}$ 纳米颗粒附着的中空碳球, 其直 径约为 $300 \sim 400 \mathrm{~nm}$, 但末大幅度改善其电化学性能.
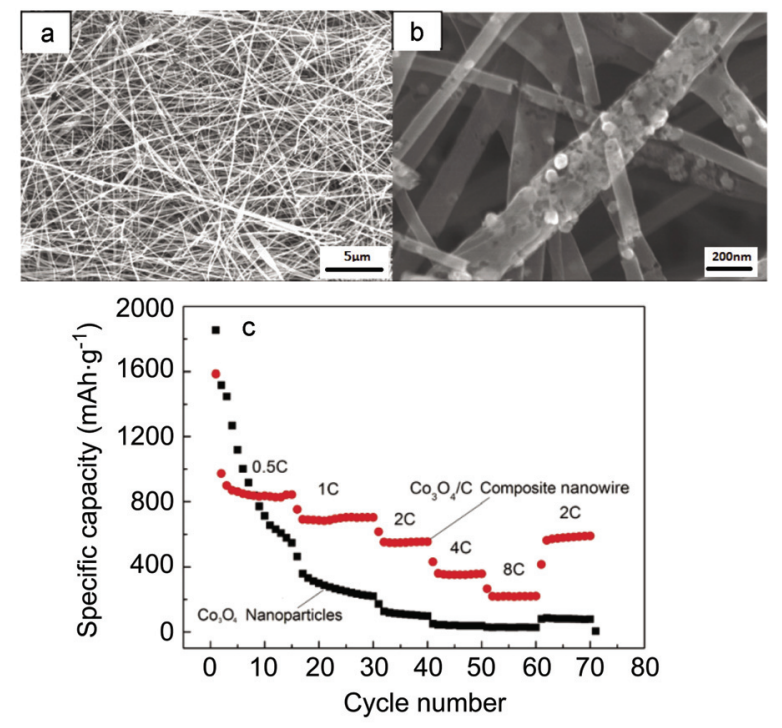

图 $5 \mathrm{Co}_{3} \mathrm{O}_{4} / \mathrm{C}$ 复合纳米线在不同放大倍数下的 $\operatorname{SEM}$ 图 $(\mathrm{a}, \mathrm{b})$ 和其在不 同倍率下的放电比容量曲线(c) ${ }^{[64]}$

Figure 5 (a) and (b) SEM images of $\mathrm{Co}_{3} \mathrm{O}_{4} / \mathrm{C}$ composite nanowires at different magnifications and (c) specific capacity of $\mathrm{Co}_{3} \mathrm{O}_{4} / \mathrm{C}$ composite nanowires at various current densities ${ }^{[64]}$

\subsection{2 $\mathrm{Co}_{3} \mathrm{O}_{4} /$ 石墨烯复合材料}

Wang 等 ${ }^{[68]}$ 以带有羧基、羟基等带电荷官能团的氧 化石墨为碳源(其与氯化钴溶液混合时, 金属离子可均 匀吸附或固定于氧化石墨表面), 接着采用 $\mathrm{NaBH}_{4}$ 为还 原剂将氧化石墨还原, 并在 $200{ }^{\circ} \mathrm{C}$ 低温炦烧 $15 \mathrm{~h}$ 后, 制 得平均粒径约为 $20 \mathrm{~nm}$ 的 $\mathrm{Co}_{3} \mathrm{O}_{4}$ 颗粒, 其均匀的附着在 石墨烯表面, 形成两者的复合材料. 在 $55 \mathrm{~mA} \cdot \mathrm{g}^{-1}$ 条件 下, 复合物初始放电容量有所下降(约为 $750 \mathrm{mAh} \cdot \mathrm{g}^{-1}$ ), 但容量保持率提高, 50 次循环后仍保持 $700 \mathrm{mAh} \cdot \mathrm{g}^{-1}$. Yang 等 ${ }^{[69]}$ 将有机金属盐酞菁钴(Cobalt Phthalocyanine) 与石墨烯氧化物混合溶解, 将前者固定在后者表面, 然 后在 $400{ }^{\circ} \mathrm{C}$ 空气氛围下煅烧, 制得 $\mathrm{Co}_{3} \mathrm{O}_{4} /$ 石墨烯复合材 料. 通过比较发现, 复合材料的容量保持率与倍率性能 大幅度提升：在 $75 \mathrm{~mA} \cdot \mathrm{g}^{-1}$ 条件下, 循环 20 次后其容量
仍保持 $800 \mathrm{mAh} \cdot \mathrm{g}^{-1}$ 以上, 而单一 $\mathrm{Co}_{3} \mathrm{O}_{4}$ 的容量已衰减 至 $400 \mathrm{mAh} \cdot \mathrm{g}^{-1}$; 在大电流 $22 \mathrm{~A} \cdot \mathrm{g}^{-1}$ 条件下充放电 10 次 后, 恢复至 $75 \mathrm{~mA} \cdot \mathrm{g}^{-1}$ 时, 复合材料容量仍可恢复至 800 $\mathrm{mAh} \cdot \mathrm{g}^{-1}$, 而 $\mathrm{Co}_{3} \mathrm{O}_{4}$ 仅有 $200 \sim 400 \mathrm{mAh} \cdot \mathrm{g}^{-1}$. Wang 等 ${ }^{[70]}$ 将石墨烯阵列加入含钴溶液中, 采用液相沉淀法与高温 煅烧法相结合制备出平均粒径为 $10 \sim 40 \mathrm{~nm}$ 的 $\mathrm{Co}_{3} \mathrm{O}_{4}$ 颗 粒, 其均匀分布在石墨烯阵列中. 在 $74.4 \mathrm{~mA} \cdot \mathrm{g}^{-1}$ 条件 下, 复合物首次放电容量约为 $1000 \mathrm{mAh} \cdot \mathrm{g}^{-1}, 100$ 次循 环后仍为 $975 \mathrm{mAh} \cdot \mathrm{g}^{-1}$, 衰减小于 $3 \%$, 大大提高了 $\mathrm{Co}_{3} \mathrm{O}_{4}$ 的容量保持率. $\mathrm{Li}$ 等 ${ }^{[71]}$ 采用上述类似方法, 合成 出颗粒尺寸为 $10 \sim 50 \mathrm{~nm}$ 的 $\mathrm{Co}_{3} \mathrm{O}_{4}$, 均匀附着在厚度为 $1.5 \mathrm{~nm}$ 的石墨烯层表面. 在 $0.2 \mathrm{C}$ 倍率条件下, 其首次放 电容量约为 $940 \mathrm{mAh} \cdot \mathrm{g}^{-1}$, 循环 60 次后, 容量约为 740 $\mathrm{mAh} \cdot \mathrm{g}^{-1}$, 保持率大于 $88 \%$. Choi 等 ${ }^{[72]}$ 将平均粒径约为 $10 \sim 35 \mathrm{~nm}$ 的 $\mathrm{Co}_{3} \mathrm{O}_{4}$ 纳米颗粒沉积在多孔石墨烯表面. 该多孔石墨烯的孔径大小可通过调节模板剂使其在 100 $\mathrm{nm} \sim 2 \mu \mathrm{m}$ 范围内可控. 在 $50 \mathrm{~mA} \cdot \mathrm{g}^{-1}$ 条件下, 其初次放 电容量为 $1100 \mathrm{mAh} \cdot \mathrm{g}^{-1}, 50$ 次循环后仍保持约 1000 $\mathrm{mAh} \cdot \mathrm{g}^{-1}$ (图 6). $\mathrm{Wu}$ 等 ${ }^{[73]}$ 采用类似方法也合成了 $\mathrm{Co}_{3} \mathrm{O}_{4} /$ 石墨烯复合物. 其特点是在不同电流密度 50, 150, 250 和 $500 \mathrm{~mA} \cdot \mathrm{g}^{-1}$ 充放电后, 恢复至 $50 \mathrm{~mA} \cdot \mathrm{g}^{-1}$ 放电时, 其 容量仍可恢复至 $800 \mathrm{mAh} \cdot \mathrm{g}^{-1}$. Yang 等 ${ }^{[74]}$ 采用电纺丝技 术以 PVP 为聚合物基底, 制备了附着 $\mathrm{Co}_{3} \mathrm{O}_{4}$ 纳米颗粒的 石墨烯纤维. 在 $100 \mathrm{~mA} \cdot \mathrm{g}^{-1}$ 条件下, 初次放电容量为 $1000 \mathrm{mAh} \cdot \mathrm{g}^{-1}, 50$ 次循环后容量仍为 $860 \mathrm{mAh} \cdot \mathrm{g}^{-1}$. Guo 等 ${ }^{[75]}$ 制备了 $\mathrm{Co}_{3} \mathrm{O}_{4} /$ 石墨烯复合材料, 且用少量镍元素掺 杂取代钴元素, 并比较了不同镍掺杂比例对材料电性能
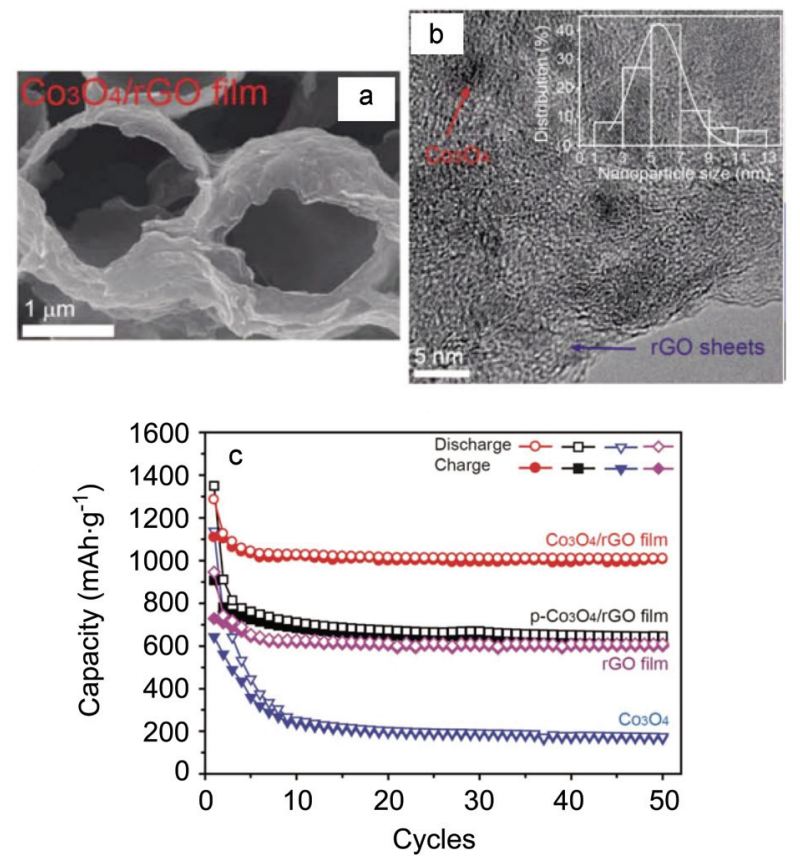

图 $6 \mathrm{Co}_{3} \mathrm{O}_{4}$ 石墨烯膜的 SEM 图(a)、TEM 图(b)和其在 $50 \mathrm{~mA} \cdot \mathrm{g}^{-1}$ 恒 电流充放电条件下的循环性能曲线 (c) ${ }^{[72]}$

Figure 6 (a) SEM image and (b) TEM image of $\mathrm{Co}_{3} \mathrm{O}_{4} /$ reduced graphene oxide (rGO) film and (c) cycling performances of $\mathrm{Co}_{3} \mathrm{O}_{4} / \mathrm{rGO}$ film at a current density of $50 \mathrm{~mA} \cdot \mathrm{g}^{-1}[72]$ 
的影响. 研究表明, 随着掺杂镍元素质量分数增至 $10 \%$, 其首次放电容量从 $640 \mathrm{mAh} \cdot \mathrm{g}^{-1}$ 增至 $875 \mathrm{mAh} \cdot \mathrm{g}^{-1}, 20$ 次循环后基本无衰减, 但若继续增加镍含量, 则体系容 量变低; 同时, 炦烧温度也影响材料电性能: 当温度为 $400{ }^{\circ} \mathrm{C}$ 时, 其电化学性能最好.

\subsection{3 $\mathrm{Co}_{3} \mathrm{O}_{4} /$ 碳纳米管复合材料}

Park 等 ${ }^{[76]}$ 采用双模板法(即硬模板法辅助溶胶凝胶 法), 将介孔碳纳米管孔隙中填满了 $\mathrm{Co}_{3} \mathrm{O}_{4}$ 纳米颗粒. 在 $100 \mathrm{~mA} \cdot \mathrm{g}^{-1}$ 条件下, 其首次放电容量为 $2200 \mathrm{mAh} \cdot \mathrm{g}^{-1}$, 第二次放电容量约为 $1200 \mathrm{mAh} \cdot \mathrm{g}^{-1}, 50$ 次循环后仍保持 在 $800 \mathrm{mAh} \cdot \mathrm{g}^{-1}$ 以上. Abbas 等 ${ }^{[77]}$ 将制备好的碳纳米管 (长度约为几微米, 管径约为 $20 \sim 30 \mathrm{~nm}$ ) 放入硝酸钴溶 液中, 采用液相沉淀法和煅烧法制得 $\mathrm{Co}_{3} \mathrm{O}_{4} /$ 碳纳米管复 合物. 在 $100 \mathrm{~mA} \cdot \mathrm{g}^{-1}$ 条件下, 其首次放电容量约为 1500 $\mathrm{mAh} \cdot \mathrm{g}^{-1}, 50$ 次循环后容量仍保持为 $870 \mathrm{mAh} \cdot \mathrm{g}^{-1}$; 当电 流密度增加至 250,350 和 $500 \mathrm{~mA} \cdot \mathrm{g}^{-1}$ 后, 其容量仍分别 为 895,834 和 $757 \mathrm{mAh} \cdot \mathrm{g}^{-1}$, 倍率性能良好(图 7). Fang 等 ${ }^{[78]}$ 采用物理法将制备好的多壁碳纳米管与 $\mathrm{Co}_{3} \mathrm{O}_{4}$ 纳 米颗粒按一定比例均匀混合. 在 $0.2 \mathrm{C}$ 倍率条件下, 其首 次放电容量约为 $1250 \mathrm{mAh} \cdot \mathrm{g}^{-1}, 70$ 次循环后容量仍大于 $900 \mathrm{mAh} \cdot \mathrm{g}^{-1}$, 其电化学性能优于混合前的 $\mathrm{Co}_{3} \mathrm{O}_{4}$ 与多 壁碳纳米管. $\mathrm{Du}$ 等 ${ }^{[79]}$ 采用超声波将碳纳米管(管径约为 $30 \sim 50 \mathrm{~nm}$ )均匀分布在含 $\mathrm{Co}(\mathrm{CO})_{12}$ 的已烷中, 其分解成 Co 单质沉淀在碳纳米管上; 然后将混合物在氧气氛围 下煓烧合成 $\mathrm{Co}_{3} \mathrm{O}_{4} /$ 碳纳米管复合物, 其电化学性能一 般. Zhou 等 ${ }^{[80]}$ 将多壁碳纳米管阵列放入硝酸钴溶液中, 采用水热法合成 $\mathrm{Co}_{3} \mathrm{O}_{4}$, 让其自然沉积在碳纳米管上.
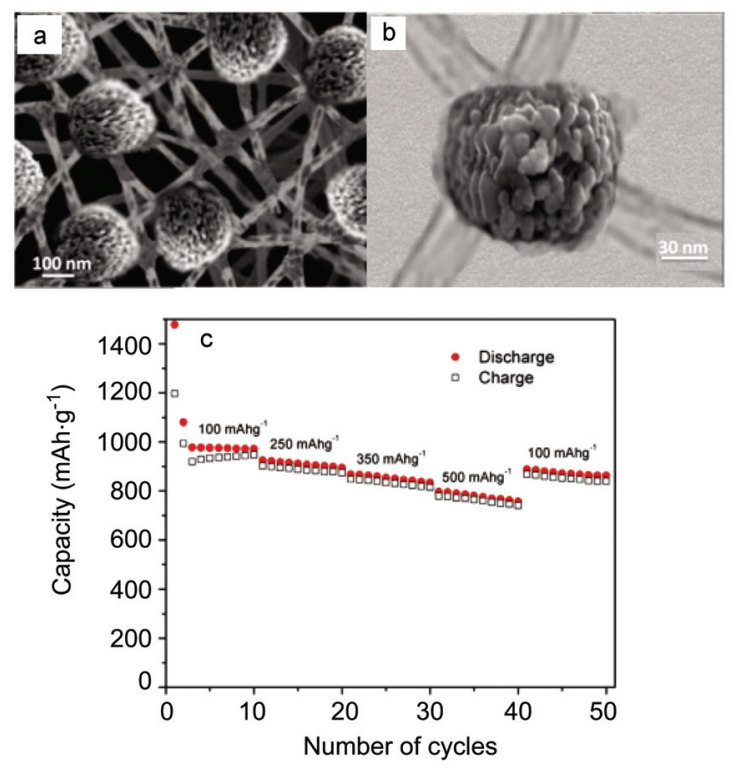

图 $7 \mathrm{Co}_{3} \mathrm{O}_{4} /$ 碳纳米管的 SEM 图(a)、TEM 图(b)和其在不同电流密度 条件下的循环性能曲线(c) ${ }^{[77]}$

Figure 7 (a) SEM image and (b) TEM image of $\mathrm{Co}_{3} \mathrm{O}_{4} /$ carbon nanotubes composite and (c) the rate capability at various current densities between 100 and $500 \mathrm{~mA} \cdot \mathrm{g}^{-1[77]}$
他们研究了不同质量比例的 $\mathrm{Co}_{3} \mathrm{O}_{4} /$ 多壁碳纳米管复合 物(40.1：1, 13.1: 1 和 $5.1: 1)$ 的电化学差异: 复合物的 容量要高于单一的 $\mathrm{Co}_{3} \mathrm{O}_{4}$ 与多壁碳纳米管; 但碳纳米管 加入量过多或者过少时，复合物的容量均会降低，存在 最优配比.

综上所述, $\mathrm{Co}_{3} \mathrm{O}_{4}$ 与碳素类的复合, 均能不同程度 的全面提高 $\mathrm{Co}_{3} \mathrm{O}_{4}$ 的电化学性能. 这可能是由于碳素材 料形成的导电网络富有弹性，与目前常用的电解液相溶 性很好, 有利于形成优化的钝化膜，同时由于弹性的碳 层包覆着整个活性粒子, 故可以有效地缓解充放电过程 中材料的体积变化, 使得复合材料可逆容量与循环稳定 性都有了很大的提高.

\section{2 含 $\mathrm{Co}_{3} \mathrm{O}_{4}$ 的其他复合材料}

$\mathrm{Wu}$ 等 ${ }^{[81]}$ 采用模板法先合成 $\mathrm{Co}_{3} \mathrm{O}_{4}$ 纳米线阵列, 然 后采用液相沉淀法将 $\mathrm{Fe}_{2} \mathrm{O}_{3}$ 颗粒附着于其表面, 形成复 合材料. 在 $100 \mathrm{~mA} \cdot \mathrm{g}^{-1}$ 条件下, 其首次放电容量约为 $1200 \mathrm{mAh} \cdot \mathrm{g}^{-1}, 60$ 次循环后容量约为 $1000 \mathrm{mAh} \cdot \mathrm{g}^{-1}$.

$\mathrm{SnO}_{2}$ 的容量与 $\mathrm{Co}_{3} \mathrm{O}_{4}$ 接近, 且其具有不与溶剂共嵌 入的优点, 故 Hassan 等 ${ }^{[82]}$ 采用熔融法, 制备了两者的无 规则片状复合材料，直径约为 $6 \mu \mathrm{m}$, 厚度小于 $5 \mathrm{~nm}$. 复 合材料的容量要高于单一的 $\mathrm{SnO}_{2}$, 略低于 $\mathrm{Co}_{3} \mathrm{O}_{4}$, 但容 量保持率大幅度提升.

$\mathrm{Si}$ 具有极高的理论比容量 $\left(4200 \mathrm{mAh} \cdot \mathrm{g}^{-1}\right)$ 与较低的 脱嵌锂电压. 故 Sun 等 ${ }^{[83]}$ 将 $\mathrm{Co}_{3} \mathrm{O}_{4}$ 纳米颗粒吸附在 $\mathrm{Si}$ 纳米阵列模板上 $(\mathrm{Si}$ 纳米线长度约为 $40 \mu \mathrm{m}$, 直径约为 $30 \sim 300 \mathrm{~nm}$ ) 形成复合材料，在 $2 \mathrm{C}$ 倍率条件下，循环 50 次后, 复合材料容量约为 $500 \mathrm{mAh} \cdot \mathrm{g}^{-1}$, 单一材料为 250 $\mathrm{mAh} \cdot \mathrm{g}^{-1}$; 在 $6 \mathrm{C}$ 倍率条件下, 复合材料容量约为单一材 料的 $2 \sim 3$ 倍.

\section{4 总结与展望}

\section{$4.1 \mathrm{Co}_{3} \mathrm{O}_{4}$ 基负极材料存在的问题}

综上所述, 现有 $\mathrm{Co}_{3} \mathrm{O}_{4}$ 及其复合材料, 虽然比容量 较高, 在低倍率下容量保持率较好, 且与碳素类材料复 合后，倍率性能有所改进. 但仍存在如下不足:

(1) 首次不可逆容量损失 $(>30 \%)$ 较大. 一般首次 放电容量为 $1000 \sim 1400 \mathrm{mAh} \cdot \mathrm{g}^{-1}$, 而首次充电容量仅为 $800 \sim 1100 \mathrm{mAh} \cdot \mathrm{g}^{-1}$. 其可能的原因为: (a)电极表面固 体电解质界面膜(SEI 膜, Solid Electrolyte Interphase)的 形成，消耗了部分活性物质; (b)部分钴离子未形成微纳 米结构, 使反应不能可逆，导致能量损耗.

(2) 材料的充放电容量高于理论值 $890 \mathrm{mAh} \cdot \mathrm{g}^{-1}$. 目前没有较明确且大家公认的解释, 可能的原因是: (a) 测试仪器的不准确，导致部分结果偏高; (b)材料的微纳 米尺寸、复合改性等手段确实提高了材料的电化学性能; (c)存在其他未知的可能的反应机理.

（3）材料倍率性能有待提高：其在低倍率或小电流 
充放电时, 容量高, 容量保持率优异; 但高倍率或大电 流条件下，容量低且循环后迅速衰减。其可能原因为: (a) 首次嵌锂后, 往往会发生体积膨胀, 产生较大的应 力, 因此颗粒间在循环过程中会逐渐失去电接触; (b)材 料自身导电性差, 在大电流或高倍率充放电条件下, 发 生严重的电极极化, 从而显著的降低了其电化学性能. (c)大量锂离子嵌入后, 体积膨胀使相邻的纳米颗粒增 加了接触的机会, 使近邻的纳米颗粒逐渐融合, 从而引 发了电化学团聚. 团聚的发生使得许多原来活性的颗粒 丧失电化学活性.

\section{2 提高 $\mathrm{Co}_{3} \mathrm{O}_{4}$ 电化学性能的有效手段}

为了改善 $\mathrm{Co}_{3} \mathrm{O}_{4}$ 的电化学性能, 研究者采用的各种 手段与方法, 概括起来主要有以下 3 点.

(1) 材料纳米化: (a)增大比表面, 增多晶体边界, 扩 大电极/电解液接触面积, 增加反应活性点; (b)颗粒尺寸 小, 使锂离子嵌入和脱出行程变短, 有利于大电流与高 倍率下充放电; (c)使绝对体积变化变小, 减小了电极在 充放电时极化程度, 抑制了嵌脱锂过程引起的体积变 化, 使材料的结构保持相对稳定, 提高了可逆容量与循 环性能. 但缺点是, 过大的表面能, 使颗粒之间容易团 聚或融合, 且反应活性点, 表面副产物易增多.

(2) 特殊形貌化: 具有特殊形貌的纳米材料, 其结 构能防止团聚现象, 保持纳米材料在循环中的结构稳 定, 提高循环性能. 特殊形貌还具有提高电极与电解液 接触面积、缩短锂离子和电子的扩散距离的优点.

(3) 复合改性: 提高 $\mathrm{Co}_{3} \mathrm{O}_{4}$ 循环性能的重要手段是 把活性物质与其它辅助物进行复合. 辅助物起到两个重 要的作用: (a)提高活性物质的导电性, 维护活性物质之 间的电接触; (b)可缓冲活性材料在充放电过程中的体积 效应和稳定活性物质的结构.

\section{$4.3 \mathrm{Co}_{3} \mathrm{O}_{4}$ 基负极材料末来的研究方向}

为了进一步提高 $\mathrm{Co}_{3} \mathrm{O}_{4}$ 的倍率性能、容量保持率及 导电性能等, 为其将来工业化应用打下基础, 并为其他 过渡金属氧化物如 $\mathrm{NiO}, \mathrm{CuO}$ 的研究提供借鉴, 我们认 为可对如下方向进行更深入的研究:

(1) 寻找通用性强的纳米/微米级 $\mathrm{Co}_{3} \mathrm{O}_{4}$ 颗粒制备技 术, 实现粒径与形貌的可控制备, 并系统地研究其电化 学性能的变化规律. 针对现有文献未系统比较不同形貌 材料在相同条件下电化学性能的差异, 我们采用液相沉 淀法, 通过选择不同的表面活性剂做载体模板, 分别合 成了花状、片状、球状与纤维状的 $\mathrm{Co}_{3} \mathrm{O}_{4}$ 材料(图 8), 并 对其电化学性能进行了初步的表征(图 9).

(2) $\mathrm{Co}_{3} \mathrm{O}_{4}$ 做锂离子电池负极材料的相关基础理论 研究. 如前所述, 其首次充电容量存在大于理论容量的 现象, 其 SEI 膜的组成及成分尚无明确报道, 其充放电 机理存在异议, 其晶体增长机理等均需要进一步的完 善.

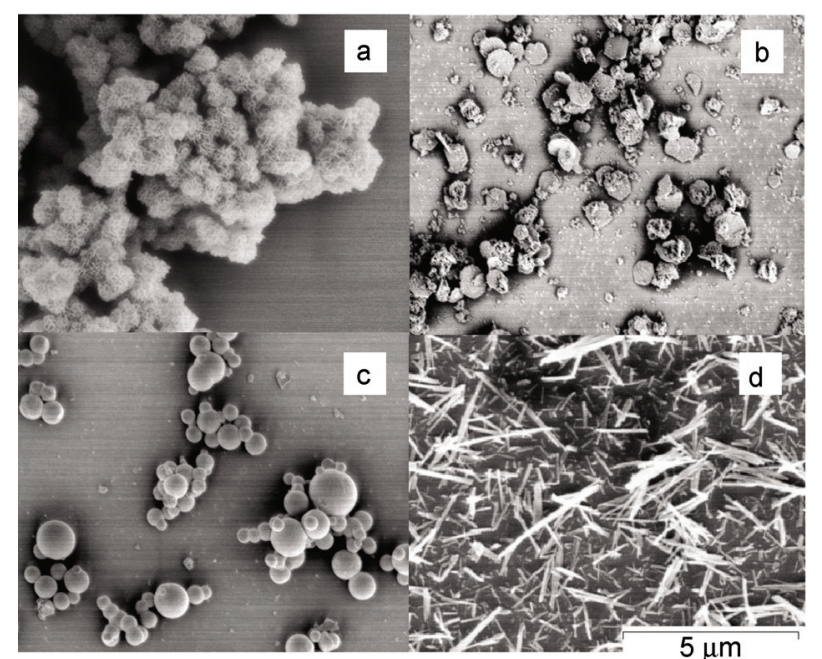

图 8 不同形貌 $\mathrm{Co}_{3} \mathrm{O}_{4}$ 的 SEM 图: (a)花状; (b)片状; (c)球状; (d)纤维状 Figure 8 SEM images of $\mathrm{Co}_{3} \mathrm{O}_{4}$ with different morphologies: (a) flowers, (b) sheets, (c) spheres, (d) wires

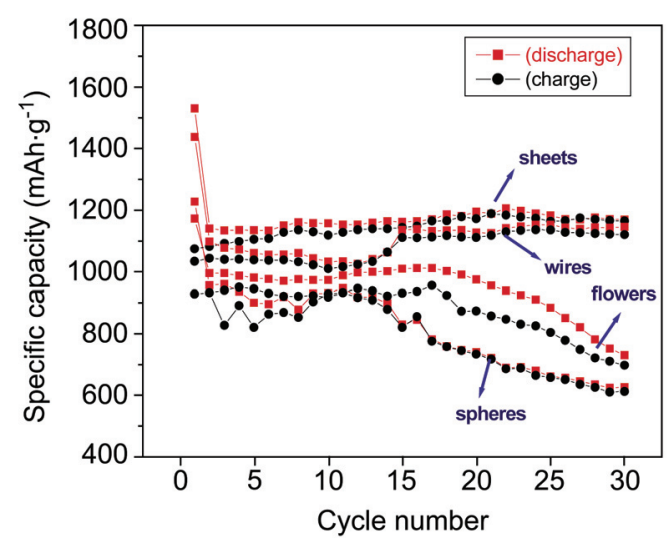

图 9 不同形貌 $\mathrm{Co}_{3} \mathrm{O}_{4}$ 的循环性能曲线 $(0.01 \sim 3.0 \mathrm{~V}, 0.1 \mathrm{C})$

Figure 9 Cycling performances of $\mathrm{Co}_{3} \mathrm{O}_{4}$ with different morphologies at a rate of $0.1 \mathrm{C}$ between $0.01 \mathrm{~V}$ and $3.0 \mathrm{~V}$

(3) $\mathrm{Co}_{3} \mathrm{O}_{4}$ 的复合改性与修饰技术尚需进一步提升. 虽然已有不少科研工作者对 $\mathrm{Co}_{3} \mathrm{O}_{4}$ 的复合改性进行了探 索性的研究, 但其结果存在进一步提高的空间, 如何解 决在充放电过程中的团聚问题、如何抑制其体积膨胀、 降低首次不可逆容量损失、提高材料导电率等难题亟待 解决.

\section{作者简介}

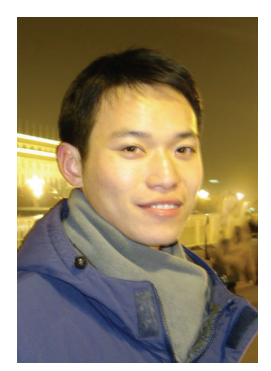

黄国勇, 男, 清华大学核能与新能源技术研究院 2012 级 在读博士研究生, 主要研究方向为锂离子电池负极材料的可 
控制备与电化学性能表征.

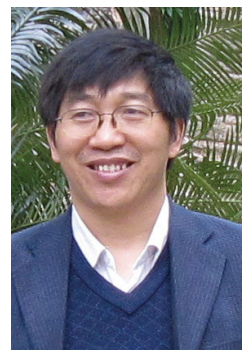

徐盛明, 男, 1963 年 9 月生, 湖南桃源人, 工学博士, 清华 大学核能与新能源技术研究院研究员, 博士生导师, 精细陶 瓷北京市重点实验室副主任、稀贵金属综合利用新技术国家 重点实验室学术委员会、中国有色金属学会冶金物理化学学 术委员会、中国稀土化学与湿法冶金专业委员会、《功能材 料》和《稀土》杂志编委会委员等学术团体职务. 先后获中南 大学有色冶金专业工学学士(1985)、硕士(1988)和博士学位 (1996). 主要从事有色金属湿法冶金、先进材料制备与循环过 程物理化学及萃取剂合成等研究.

\section{References}

[1] Dunn, B.; Kamath, H.; Tarascon, J. M. Science 2011, 334, 928.

[2] Chen, J. J. Materials 2013, 6, 156.

[3] Volder, M. F. L. D.; Tawfick, S. H.; Baughman, R. H.; Hart, A. J. Science 2013, 535, 339.

[4] Xiong, Z. L.; Yun, Y. S.; Jin, H. J. Materials 2013, 6, 1138.

[5] Lee, Y. J.; Yi, H.; Kim, W. J.; Kang, K.; Yun, D. S.; Strano, M. S.; Ceder, G.; Belcher, A. M. Science 2009, 324, 1051.

[6] Cai, D. D.; Wang, S. Q.; Lian, P. C.; Zhu, X. F.; Li, D. D.; Yang, W. S.; Wang, H. H. Electrochim. Acta 2013, 90, 492.

[7] Xu, Y. H.; Liu, Q.; Zhu, Y. J.; Liu, Y. H.; Langrock, A.; Zachariah, M. R.; Wang, C. S. Nano Lett. 2013, 13, 470.

[8] Enrique, Q. G.; Jürgen, C.; Helmut, F. Materials 2013, 6, 626.

[9] Xue, L. G.; Fu, Z. H.; Yao, Y.; Huang, T.; Yu, A. S. Electrochim. Acta 2010, 55, 7310 .

[10] Lee, Y. J.; Lee, Y. J.; Oh, D.; Chen, T.; Ceder, G.; Belcher, A. M. Nano Lett. 2010, 10, 2433.

[11] Idota, Y.; Kubota, T.; Matsufuji, A.; Maekawa, Y.; Miyasaka, T. Science 1997, 276, 1395.

[12] Gu, Y.; Xu, Y.; Wang, Y. ACS Appl. Mater. Interfaces 2013, 5, 801

[13] Xiao, J.; Choi, D.; Cosimbescu, L.; Koech, P.; Liu, J.; Lemmon, J. P. Chem. Mater. 2010, 22, 4522.

[14] Zhang, X. N.; Pan, G. L.; Li, G. R.; Qu, J. Q.; Gao X. P. Solid State Ionics 2007, 178, 1107.

[15] Cui, Y. H.; Xue, M. Z.; Fu, Z. W.; Wang, X. L.; Liu, X. J. J. Alloys Compd. 2013, 555, 283.

[16] Kim, Y.; Hwang, H.; Yoon, C. S.; Kim, M. G.; Cho, J. Adv. Mater. 2007, 19, 92.

[17] Yan, H.; Zhu, Z.; Zhang, D.; Li, W.; Lu, Q. J. Power Sources 2012, 219, 45.

[18] Sun, S. J.; Wen, Z. Y.; Jin, J.; Cui, Y. M.; Lu, Y. Microporous Mesoporous Mater. 2013, 169, 242.

[19] Liu, B.; Zhang, J.; Wang, X. F.; Chen, G.; Chen, D.; Zhou, C. W.; Shen, G. Z. Nano Lett. 2012, 12, 3005.

[20] Hu, L.; Zhong, H.; Zheng, X. R.; Huang, Y. M.; Zhang, P.; Chen, Q. W. Sci. Rep. 2012, $2,1$.

[21] Bai, Z. C.; Fan, N.; Sun, C. H.; Ju, Z. C.; Guo, C. L.; Yang, J.; Qian, Y. T. Nanoscale 2013, 5, 2442.

[22] Wu, H. B.; Chen, J. S.; Hng, H. H.; Lou, X. W. Nanoscale 2012, 4, 2526.

[23] Li, W. J.; Fu, Z. W. Appl. Surf. Sci. 2010, 256, 2447.

[24] Li, X. L.; Song, H. F.; Wang, H.; Zhang, Y. L.; Du, K.; Li, H. Y.; Huang, J. M. J. Appl. Electrochem. 2012, 42, 1065.

[25] Li, W. Y.; Xu, L. N.; Chen, J. Adv. Funct. Mater. 2005, 15, 851.
[26] Shaju, K. M.; Jiao, F.; De'bart, A.; Bruce, G. P. Phys. Chem. Chem. Phys. 2007, 9, 1837.

[27] Wang, F.; Lu, C. C.; Qin, Y. F.; Liang, C. C.; Zhao, M. S.; Yang, S. C.; Sun, Z. B.; Song, X. P. J. Power Sources 2013, 235, 67.

[28] Zhang, M.; Jia, M. Q.; Jin, Y. H.; Shi, X. R. Appl. Surf. Sci. 2012, 263, 573.

[29] Wu, Y.; Wei, Y.; Wang, J. P.; Jiang, K. L.; Fan, S. S. Nano Lett. 2013, 13,818 .

[30] Li, Y.; Zhu, C. L.; Lu, T.; Guo, Z. P.; Zhang, D.; Ma, J.; Zhu, S. M. Carbon 2013, 52, 565.

[31] Zhang, G. H.; Chen, Y. J.; Qu, B. H.; Hu, L. L.; Mei, L.; Lei, D. N.; Li, Q.; Chen, L. B.; Li, Q. H.; Wang, T. H. Electrochim. Acta 2012, $80,140$.

[32] Huang, X. H.; Tu, J. P.; Zhang, C. Q.; Zhou, F. Electrochim. Acta 2010, 55, 8981.

[33] Zhong, K. F.; Zhang, B.; Luo, S. H.; Wen, W.; Li, H.; Huang, X. J.; Chen, L. Q. J. Power Sources 2011, 196, 6802.

[34] Wang, J. Z.; Du, N.; Wu, H.; Zhang, H.; Yu, J. X.; Yang, D. R. J. Power Sources 2013, 222, 32.

[35] Wang, L. L.; Gong, H. X.; Wang, C. H.; Wang, D.; Tang, K. B.; Qian, Y. T. Nanoscale 2012, 4, 6850.

[36] Liu, D. Q.; Yang, Z. B.; Wang, P.; Li, F.; Wang, D. S.; He, D. Y. Nanoscale 2013, 5, 1917.

[37] Poizot, P.; Laruelle, S.; Grugeon, S.; Dupont, L.; Tarascon, J. M. Nature 2000, 407, 496.

[38] Sun, Y.; Feng, X. Y.; Chen, C. H. J. Power Sources 2011, 196, 784.

[39] Wang, J. Y.; Yang, N. L.; Tang, H. J.; Dong, Z. H.; Jin, Q.; Yang, M.; Kisailus, D.; Zhao, H. J.; Tang, Z. Y.; Wang, D. Angew. Chem. 2013, $125,1$.

[40] Hong, S. H.; Bae, J. S.; Ahn, H. J. Met. Mater. Int. 2008, 14, 229.

[41] Zhao, W. W.; Liu, Y.; Li, H. L.; Zhang, X. G. Mater. Lett. 2008, 62, 772 .

[42] Zhan, F. M.; Geng, B. Y.; Guo, Y. J. Chem. Eur. J. 2009, 15, 6169.

[43] Lu, Y.; Wang, Y.; Zou, Y. Q.; Jiao, Z.; Zhao, B.; He, Y. Q.; Wu, M. H. Electrochem. Commun. 2010, 12, 101.

[44] Yan, N.; Hu, L.; Li, Y.; Wang, Y.; Zhong, H.; Hu, X. Y.; Kong, X. K.; Chen, Q. W. J. Phys. Chem. C 2012, 116, 7227.

[45] Dong, Q.; Kumada, N.; Yonesaki, Y.; Takei, T.; Kinomura, N. Mater. Res. Bull. 2011, 46, 1156.

[46] Tian, L.; Huang, K. L.; Liu, Y. N.; Liu, S. Q. J. Solid State Chem. 2011, 184, 2961.

[47] Li, Y. L.; Zhao, J. Z.; Dan, Y. Y.; Ma, D. C.; Zhao, Y.; Hou, S. N.; Lin, H. B.; Wang, Z. C. Chem. Eng. J. 2011, 166, 428.

[48] Nam, K. T.; Kim, D. W.; Yoo, P. J.; Chiang, C. Y.; Meethong, N.; Hammond, P. T.; Chiang, Y. M.; Belcher, A. M. Science 2006, 312, 885.

[49] Shim, H. W.; Jin, Y. H.; Seo, S. D.; Lee, S. H.; Kim D. W. ACS Nano 2011, 5, 443 .

[50] Li, C. C.; Yin, X. M.; Chen, L. B.; Li, Q. H.; Wang, T. H. Chem. Eur. J. 2010, 16, 5215.

[51] Wang, Y.; Xia, H.; Lu, L.; Lin, J. Y. ACS Nano 2010, 4, 1425.

[52] Li, Y. G.; Tan, B.; Wu, Y. Y. Nano Lett. 2008, 8, 256.

[53] Xue, X. Y.; Yuan, S.; Xing, L. L.; Chen, Z. H.; He, B.; Chen, Y. J. Chem. Commun. 2011, 47, 4718.

[54] Lou, X. W.; Deng, D.; Lee, J. Y.; Feng, J.; Archer, L. A. Adv. Mater. 2008, 20, 258.

[55] Ding, Y. H.; Zhang, P.; Long, Z. L.; Jiang, Y.; Huang, J. N.; Yan, W. J.; Liu, G. Mater. Lett. 2008, 62, 3410.

[56] Xu, R.; Wang, J. W.; Li, Q. Y.; Sun, G. Y.; Wang, E. B.; Li, S. H.; Gu, J. M.; Ju, M. L. J. Solid State Chem. 2009, 182, 3177.

[57] Keng, P. Y.; Kim, B. Y.; Shim, I. B.; Sahoo, R.; Veneman, P. E.; Armstrong, N. R.; Yoo, H.; Pemberton, J. E.; Bull, M. M.; Griebel, J. J.; Ratcliff, E. L.; Nebesny, K. G.; Pyun, J. ACS Nano 2009, 3, 3143.

[58] Xu, M. W.; Wang, F.; Zhao, M. S.; Yang, S.; Song, X. P. Electrochim. Acta 2011, 56, 4876.

[59] Chou, S. L.; Wang, J. Z.; Liu, H. K.; Dou, S. X. J. Power Sources 2008, $182,359$.

[60] Rui, X. H.; Tan, H. T.; Sim, D. H.; Liu, W. L.; Xu, C.; Hng, H. H.; Yazami, R.; Lim, T. M.; Yan, Q. Y. J. Power Sources 2013, 222, 97.

[61] Xiong, S. L.; Chen, J. S.; Lou, X. W.; Zeng, H. C. Adv. Funct. Mater. 2012, 22, 861 .

[62] Wang, L. M.; Liu, B.; Ran, S. H.; Huang, H. T.; Wang, X. F.; Liang, B.; Chen, D.; Shen, G. Z. J. Mater. Chem. 2012, 22, 23541.

[63] Wang, S. J.; Zhang, B. P.; Zhao, C. H.; Li, S. J.; Zhang, M. X.; Yan, L. P. Appl. Surf. Sci. 2011, 257, 3358. 
[64] Zhang, P.; Guo, Z. P.; Huang, Y. D.; Jia, D. Z.; Liu, H. K. J. Power Sources 2011, 196, 6987.

[65] Wang, X.; Guan, H.; Chen, S.; Li, H. Q.; Zhai, T. Y.; Tang, D. M.; Bando, Y.; Golberg, D. Chem. Commun. 2011, 47, 12280

[66] Wang, Y. F.; Zhang, L. J. J. Power Sources 2012, 209, 20.

[67] Zhan, L.; Wang, Y. L.; Qiao, W. M.; Ling, L. C.; Yang, S. B. Electrochim. Acta 2012, 78, 440.

[68] Wang, B.; Wang, Y.; Park, J.; Ahn, H.; Wang, G. X. J. Alloys Compd. 2011, 509, 7778 .

[69] Yang, S. B.; Cui, G. L.; Pang, S. P.; Cao, Q.; Kolb, U.; Feng, X. L.; Maier, J.; Mullen, K. ChemSusChem 2010, 3, 236.

[70] Wang, G. L.; Liu, J. C.; Tang, S.; Li, H. Y.; Cao, D. X. J. Solid State Electrochem. 2011, 15, 2587.

[71] Li, B. Y.; Cao, H. Q.; Shao, J.; Li, G. Q.; Qu, M. Z.; Yin, G. Inorg. Chem. 2011, 50, 1628.

[72] Choi, B. G.; Chang, S. J.; Lee, Y. B.; Bae, J. S.; Kim, H. J.; Huh, Y. S. Nanoscale 2012, 4, 5924.

[73] Wu, Z. S.; Ren, W. C.; Wen, L.; Gao, L. B.; Zhao, J. P.; Chen, Z. P.; Zhou, G. M.; Li, F.; Cheng, H. M. ACS Nano 2010, 4, 3187.

[74] Yang, X. L.; Fan, K. C.; Zhu, Y. H.; Shen, J. H.; Jiang, X.; Zhao, P.;
Luan, S. R.; Li, C. Z. ACS Appl. Mater. Interfaces 2013, 5, 997.

[75] Guo, H. J.; Li, X. H.; Xie, J.; Wang, Z. X.; Peng, W. J.; Sun, Q. M. Energy Convers. Manage. 2010, 51, 247.

[76] Park, J.; Moon, W. G.; Kim, G. P.; Nam, I.; Park, S.; Kim, Y.; Yi, J. Electrochim. Acta 2013, 105, 110.

[77] Abbas, S. M.; Hussain, S. T.; Ali, S.; Ahmad, N.; Ali, N.; Munawar, K. S. Electrochim. Acta 2013, 105, 481.

[78] Fang, Z. G.; Xu, W. W.; Huang, T.; Li, M. L.; Wang, W. R.; Liu, Y. P.; Mao, C. C.; Meng, F. L.; Wang, M. J.; Cheng, M. H.; Yu, A. S.; Guo, X. H. Mater. Res. Bull. 2013, 48, 4419.

[79] Du, N.; Zhang, H.; Chen, B. D.; Wu, J. B.; Ma, X. Y.; Liu, Z. H.; Zhang, Y. Q.; Yang, D. R.; Huang, X. H.; Tu, J. P. Adv. Mater. 2007, $19,4505$.

[80] Zhou, G. M.; Li, L.; Zhang, Q.; Li, N.; Li, F. Phys. Chem. Chem. Phys. 2013, 15, 5582.

[81] Wu, H.; Xu, M.; Wang, Y. C.; Zheng, G. F. Nano Res. 2013, 6, 167.

[82] Hassan, M. F.; Guo, Z. P.; Du, G. D.; Wexler. D.; Liu, H. K. Phys. Status Solidi A 2009, 206, 2546.

[83] Sun, F.; Huang, K.; Liu, Y. P.; Gao, T.; Han, Y. N.; Zhong, J. X. Appl. Surf. Sci. 2013, 266, 300. 